\title{
Knowledge and perception about tuberculosis among children attending primary school in Ntcheu District, Malawi
}

This article was published in the following Dove Press journal:

Journal of Multidisciplinary Healthcare

24 March 2016

Number of times this article has been viewed

\section{Peter Nyasulu ${ }^{1,3}$ \\ Susan Kambale ${ }^{2}$ \\ Tobias Chirwa ${ }^{3}$ \\ Teye Umanah ${ }^{3}$ \\ Isaac Singini ${ }^{4}$ \\ Simon Sikwese ${ }^{5}$ \\ Hastings T Banda ${ }^{6}$ \\ Rhoda $\mathrm{P}$ Banda $^{7}$ \\ Henry Chimbali ${ }^{8}$ \\ Bagrey Ngwira ${ }^{9}$ \\ Alister Munthali ${ }^{10}$}

'Department of Public Health, School of Health Sciences, Monash University, Johannesburg, South Africa; ${ }^{2}$ World Health Organization, Country Office, Lilongwe, Malawi; ${ }^{3}$ School of Public Health, Faculty of Health Sciences, University of the Witwatersrand, Johannesburg, South Africa; ${ }^{4}$ Johns Hopkins Research Project, College of Medicine, University of Malawi, ${ }^{5}$ Pakachere Institute of Health and Development Communication, Blantyre, ${ }^{6}$ Research for Equity and Community Health (REACH) Trust, Lilongwe, ${ }^{7}$ National Tuberculosis Control Program, Community Health Sciences Unit, Ministry of Health, Lilongwe, ${ }^{8} \mathrm{Health}$ Promotion Section, Ministry of Health, Lilongwe, ${ }^{9}$ Department of Community Health, College of Medicine, University of Malawi, Blantyre, ${ }^{10} \mathrm{Centre}$ for Social Research, University of Malawi, Zomba, Malawi

Correspondence: Peter Nyasulu Department of Public Health, School of Health Sciences, Monash University, I 44 Peter Road, Ruimsig, Johannesburg, South Africa

Email peter.nyasulu@monash.edu
Background: Knowledge and perceptions about tuberculosis (TB) can influence care-seeking behavior and adherence to treatment. Previous studies in Malawi were conducted to assess knowledge and attitudes regarding TB in adults, with limited data on knowledge in children. Objectives: This study assessed knowledge and perceptions about TB in children aged 10-14 years attending primary school in Ntcheu District, Malawi.

Design: A cross-sectional study was conducted in four primary schools in Ntcheu District. Data on knowledge and perception of TB were collected using a structured questionnaire. Pearson chi-square test was used to determine the association between socioeconomic factors and TB knowledge and perception. A $P<0.05$ was considered significant.

Results: The study found that the learners had high knowledge regarding the cause, spread, and TB preventive measures. Almost $90 \%$ of learners knew that TB is caused by a germ, however, a lower proportion knew about TB symptoms ie, night sweats (49\%) and enlarged cervical lymph nodes $(40 \%)$. We found that $68 \%$ of learners did not know the duration of anti-TB treatment. No association was found between age, learners' grade, and knowledge $(P>0.05)$.

Conclusion: Lack of knowledge regarding TB and gaps identified, may be due to a deficiency in the content of the school curriculum or the availability of information, education, and communication materials. This is the first study to report on knowledge and perceptions of TB among primary school learners in Malawi. These results will inform the development of relevant information, education, and communication materials to enhance awareness about TB among school going children.

Keywords: tuberculosis, knowledge, perceptions, health seeking, adherence, Malawi

\section{Background}

Tuberculosis (TB) was declared a global public health emergency in $1993 .{ }^{1}$ It is the second leading cause of death from infectious diseases worldwide and accounts for 7-8 million cases and 1.3 to 1.6 million deaths per year. Children account for a significant proportion of the global burden of TB. The World Health Organization (WHO) estimates that children under 15 years of age accounted for $11 \%$ of all the TB cases that occurred globally in $2005 .^{2}$ Childhood TB accounts for about $20 \%-40 \%$ of cases in high-burden countries, ${ }^{3}$ with the majority of children aged $\leq 15$ years reported to have smear-negative TB in 2007 in Africa and South East Asia. ${ }^{4}$

The risk of developing active TB is also higher in children, with about $40 \%-50 \%$ of infants and $15 \%$ of older children developing TB within 2 years of infection. ${ }^{5}$ Household contact with a sputum-positive adult has been found to increase the risk of TB infection and clinical disease in children. ${ }^{6,7}$ Altet et al, ${ }^{8}$ found an association between passive 
smoking in children and development of active pulmonary disease following infection. Sinfield et $\mathrm{al}^{7}$ found a TB infection rate of $45 \%$ among childhood contacts for children who are 5 years old or younger in Malawi. ${ }^{7}$ A local study among all new TB patients in a rural district hospital also found a co-infection rate of $77 \% .{ }^{9}$ People who are infected with HIV are 20 to 27 times more likely to develop TB disease in their lifetime than those who are not HIV-positive. ${ }^{10}$

The primary school curriculum also aims to address key health and development health problems facing the country. In the current syllabus which has been in use since 2007, TB is only mentioned in a sentence at the end of a chapter in the subject of agriculture in Standard 7, as one of the diseases that can affect farm animals. The absence of TB in the primary school curriculum as a health problem that affects people in Malawi is a major gap in a country where both TB incidence and TB/HIV co-infection rates are high. ${ }^{1,11}$ Previous studies have shown low levels of awareness of TB risks as well as TB treatment. ${ }^{12,13}$ This shows that there is a lack of sufficient data on knowledge of TB globally, more specifically among school children, and in Malawi such data are sparse. Bond et al, ${ }^{14}$ in 2010 found wide-ranging knowledge about $\mathrm{TB}$ in Zambia, with younger children being less sure about diagnosis, duration of TB treatment, and the link between TB and HIV. A study by Naidoo and Taylor, identified an association between learners' knowledge of TB symptoms (such as cough lasting longer than 3 weeks, night sweats, coughing out blood) and transmission with increased likelihood of intent of encouraging family members to seek and adhere to TB treatment. ${ }^{15}$

Studies conducted in some African countries reveal perceived non-biomedical causes of TB that are rooted in cultural beliefs. Spirits, bewitchment, careless sexual behavior, "God's will", bad luck, and stagnant water have, for example, been reported by some studies in Malawi, Ethiopia, and Botswana. ${ }^{16-18}$ Such beliefs may influence TB care-seeking behavior. For example, a study about TB patients in Botswana found that $34 \%$ sought care from traditional or faith healers before initiation of TB treatment at a health facility, while in Malawi 32\% had visited a traditional healer before the diagnosis of TB was made. ${ }^{18,19}$ A study in Malawi reveals cultural explanations of factors that can hinder cure from TB. ${ }^{20}$ Traditional healers also claim to be able to cure TB. ${ }^{21}$ Such deficiencies in knowledge and the wrong perceptions about the cause and cure of TB can have a negative impact on care-seeking and treatment adherence. As such the content of the primary school curriculum aims to equip pupils with the necessary knowledge, skills, and attitudes to understand how to prevent and control diseases prevalent in Malawi. There seems, however, to be a major gap in the TB content in the primary school curriculum, and there is no documentation on the knowledge and perceptions about TB among children in Malawi.

Therefore, the objectives of this study were to assess the level of knowledge and perceptions of school children aged 10-14 years about TB, as well as to determine the socioeconomic factors associated with knowledge and perception of TB in the four primary schools in the catchment area of Chiefs' Makwangwala and Ganya in Ntcheu District in April 2012.

\section{Methodology Study design}

This was an analytical cross-sectional study. This design was the most appropriate choice as the study intended to measure the levels of knowledge and perceptions about TB among primary school children, as well as determine associations between variables.

\section{Study population}

The study population comprised learners (boys and girls) attending Standard 5-8 (senior primary school) who were aged between 10 and 14 years.

\section{Study setting}

The study took place in Traditional Authority (TA) areas of Makwangwala and Ganya in Ntcheu District (Figure 1). This district was selected on the basis of high prevalence of TB. Ntcheu is a rural district with an estimated population of 499,936 people, of whom 64,207 are aged between 10 and 14 years. $^{22}$

\section{Sampling procedure}

Of the nine TAs in the district, Makwangwala and Ganya and corresponding primary schools where the study took place were selected using simple random sampling strategy. The sampling frame comprised all primary schools under the TAs Makwangwala and Ganya. The schools were identified using the 2008 National Statistics Enumeration Areas. The schools under each TA were arranged in alphabetical order and assigned numbers, then two schools in each TA were randomly selected and all pupils at each of the four selected schools were interviewed by the research assistants. Based on the sample number, 28-29 pupils (seven to eight per class) who attended classes on the day of data collection were randomly selected and interviewed at each of the four 


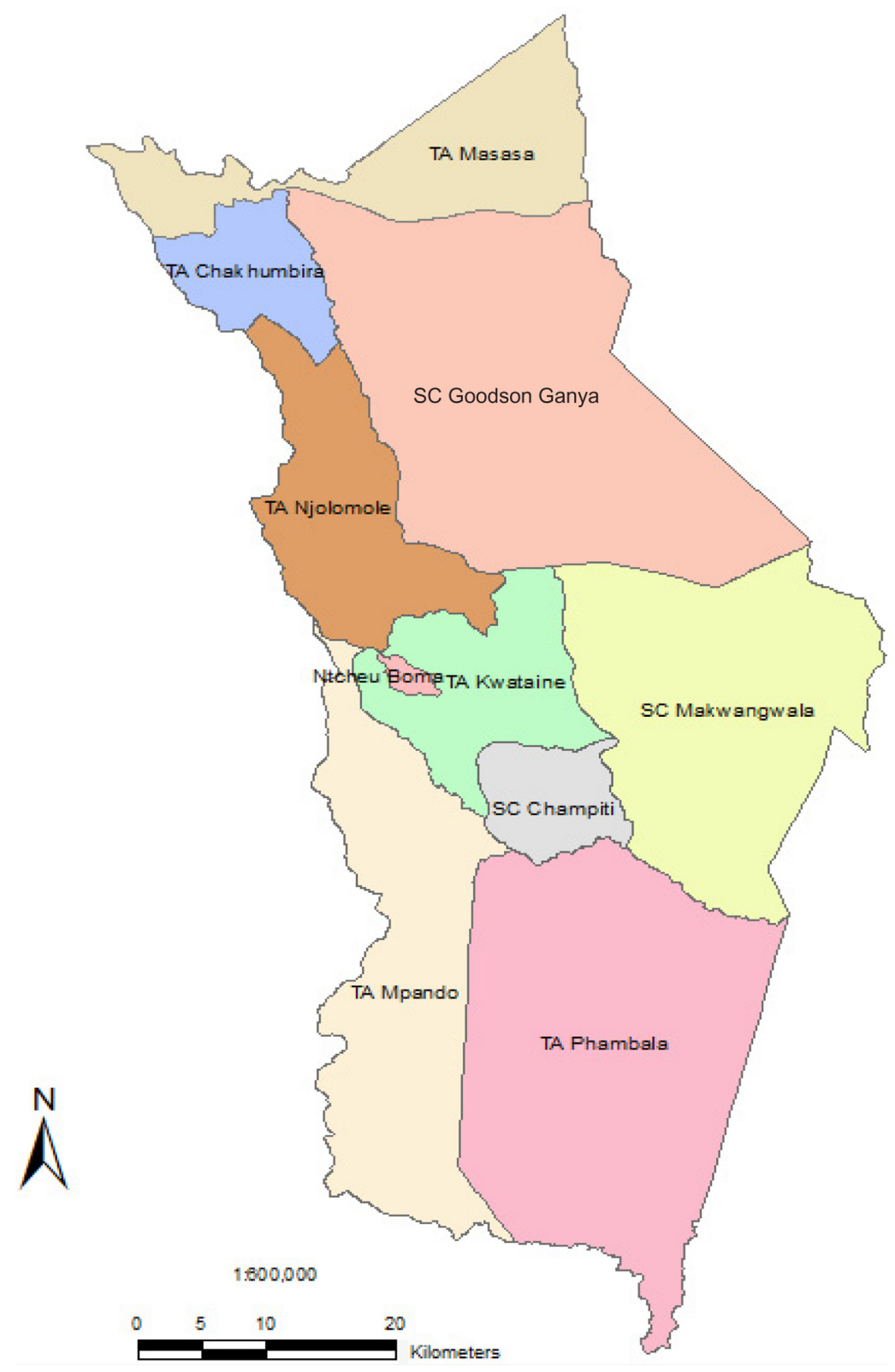

Figure I Map of Ntcheu District showing Traditional Authorities.

Abbreviations: TA, Traditional Authority; SC, Sub-Chiefdom.

schools that participated in the study. Learners in junior primary school (below Standard 5) and those in Standards 5 to 8 , but outside the age bracket of 10-14 years, were not included in the study.

\section{Sample size}

Based on the estimated population of 64,207 , regardless of sex and using the formula for sample size calculation for prevalence surveys ${ }^{23}$ the sample size (n) was calculated as follows:

$$
\mathrm{n}=\left(t^{2} \times p(1-p)+r\right) / m^{2}
$$

The following assumptions were made in the calculation of the sample: a) the highest level of knowledge of TB among the learners was $60 \%$. The $60 \%$ estimate was based on the 2010 Malawi Demographic and Health Survey finding that $67.7 \%$ of individuals aged $15-19$ years knew that TB can be cured. ${ }^{24}$ Since the population in the study was younger, it was assumed that the learners would be less knowledgeable than those in the age group 15-19 in the general population; b) the lowest level of knowledge of TB among the pupils $(p)$ was $50 \%$; c) margin of error $(m)$ of $10 \%$; d) non-response rate $(r)$ due to lack of interest in the study or other factor was $20 \%$; and e) $t=$ confidence level at $95 \%$ (standard value of 1.96). 
Factoring these parameters into the aforementioned formula, a minimum sample size of 96 pupils was obtained and taking into account a $20 \%$ non-response rate, the total number of pupils included in the study was therefore 115 .

\section{Data collection}

Data were collected from April 16-17, 2012 by trained research assistants who interviewed the learners using a closed-ended questionnaire which was translated into the local language. Assessment of knowledge was focused on the cause, mode of transmission, symptoms, risk factors, where to get help if sick with TB, ways of preventing TB, and curability of TB. Knowledge was assessed on nine symptoms: cough with sputum longer than 2 weeks; coughing out blood; fever with night sweats; general weakness; weight loss; loss of appetite; chest pain; shortness of breath; and enlarged neck glands. Assessment of perceptions focused on perceived susceptibility to TB, perceived benefits and perceived barriers affecting disclosure of TB. Assessment of knowledge and perceptions were based on dichotomous responses of either (yes/no) to presence or absence of each individual attribute. Independent factors obtained included demographic characteristics: age, sex, religion, and tribe; and socio-economic characteristics: name of school, class of pupil (ie, Standard 5, 6, 7, 8), and guardian's occupation. Parental consent and learners' assent were obtained for each participant.

\section{Data processing and analysis}

The data were entered into Epi Info version 3.5.3 database. During data collection, the filled questionnaires were checked for completeness, legibility, and missing values that could be corrected. Descriptive statistics were used primarily to summarize and describe data. Analytical statistics were used to assess the association between dependent and independent variables. Pearson chi-square test was used to determine this association and $P<0.05$ was considered significant.

\section{Validity and reliability}

In this study, the questionnaire was translated into Chichewa, a locally spoken language which is also taught in schools. A different person back-translated the study tool to English to ensure the same concepts were retained. Training of data collectors of the questionnaire was done by TB and information and communication experts. The tool was pilot tested at Kadamsana Primary School within TA Makwangwala among learners who were similar to the intended participants from the sampled schools prior to data collection. The pilot test was done on April 11, 2012. Lessons learnt in the pretest were used to modify the questionnaire accordingly.

\section{Ethical considerations}

The study was approved by the National Health Sciences Research Committee, Ministry of Health, Lilongwe, Malawi. Each participant provided written consent prior to commencing the study.

\section{Results}

\section{Distribution of characteristics of the study population}

A total of 116 learners from four primary schools participated in the study. Of these, three learners were excluded from the analysis due to their ages being out of standard range acceptable for primary school attendance. Therefore, 113 learners were included in the analysis, mean age of 12.8 years, standard deviation 1.1. The enrollment in Standards 5 to 8 in the four schools showed that $54.9 \%$ $(n=62)$ of learners were girls, reflecting that sex was not taken into account in the sampling methodology (Table 1). There were more boys than girls $(21.6 \%$ [11/51] vs $11.3 \%$ [7/62]) aged 10 to 11 years and more girls aged 13 to 14 years $(66.1 \%$ [41/62] vs $56.9 \%$ [29/51]) (data not shown).

\section{Exposure to TB information}

Ninety-nine percent of the learners $(n=112)$ had heard about $\mathrm{TB}$, and $50 \%(\mathrm{n}=56)$ of the learners indicated that they had never known anyone suffering from TB. The three main sources of TB information for the learners were learning at school $(49 \%, \mathrm{n}=55)$, health workers $(23 \%, \mathrm{n}=26)$, and radio $(16 \%, n=18)$. Other sources were relatives $(8 \%, n=9)$, friends $(1.8 \%, \mathrm{n}=2)$, and others $(1.8 \%, \mathrm{n}=2)$ (Table 1$)$.

\section{Knowledge on cause, spread, and cure of TB}

Eighty-eight percent of the learners said TB is caused by a germ. Other relatively and commonly mentioned causes were bad luck, spirits, and heredity (Figure 2). Seventy-one percent of the learners $(n=80)$ indicated that TB is a communicable disease. Eighty-one percent $(n=92)$ said TB is spread by droplets through coughing and sneezing. Variations in knowledge that TB is a communicable disease were noted among the schools. About $22 \%$ of all the learners who knew this information were from Nsiyaludzu Primary School. Ninety-seven percent of the learners $(n=109)$ stated 
Table I Frequency distribution of characteristics of primary school learners

\begin{tabular}{|c|c|}
\hline Characteristic & $* \mathbf{N}(\%)$ \\
\hline \multicolumn{2}{|l|}{ Age in years } \\
\hline$\leq 11$ & $18(15.9)$ \\
\hline 12 & $25(22.1)$ \\
\hline 13 & $29(25.7)$ \\
\hline 14 & $4 I(36.3)$ \\
\hline \multicolumn{2}{|l|}{ Girls enrollment } \\
\hline Standard 5 & $14(22.6)$ \\
\hline Standard 6 & $15(24.2)$ \\
\hline Standard 7 & $19(30.6)$ \\
\hline Standard 8 & $14(22.6)$ \\
\hline \multicolumn{2}{|c|}{ Boys enrollment } \\
\hline Standard 5 & $14(27.5)$ \\
\hline Standard 6 & $13(25.5)$ \\
\hline Standard 7 & $9(17.6)$ \\
\hline Standard 8 & $15(29.4)$ \\
\hline \multicolumn{2}{|c|}{ Class enrollment } \\
\hline Standard 5 & $28(24.8)$ \\
\hline Standard 6 & $28(24.8)$ \\
\hline Standard 7 & $28(24.8)$ \\
\hline Standard 8 & $29(25.6)$ \\
\hline \multicolumn{2}{|l|}{ Name of school } \\
\hline Chauta & $29(25.7)$ \\
\hline Chimvano & $29(25.7)$ \\
\hline Namitengo & $30(26.5)$ \\
\hline Nsiyaludzu & $25(22.1)$ \\
\hline \multicolumn{2}{|c|}{ Heard about TB? } \\
\hline Yes & $112(99.0)$ \\
\hline No & I (I.0) \\
\hline \multicolumn{2}{|c|}{ Source of information } \\
\hline School & $55(49.1)$ \\
\hline Health worker & $26(23.2)$ \\
\hline Radio & $18(16.1)$ \\
\hline Relatives & $9(8.0)$ \\
\hline Friend & $2(1.8)$ \\
\hline Other & $2(1.8)$ \\
\hline \multicolumn{2}{|c|}{ Knowledge on cure } \\
\hline Yes & $109(97.3)$ \\
\hline No & $3(2.7)$ \\
\hline \multicolumn{2}{|l|}{ Who gets TB } \\
\hline Anyone & $109(96.5)$ \\
\hline PLWHIV & $4(3.5)$ \\
\hline
\end{tabular}

Notes: $* N=113$, total number of children who participated in the study; $\%=$ percentage of $\mathrm{N}$.

Abbreviations: TB, tuberculosis; PLWHIV, people living with HIV.

that TB is curable, and $95 \%(n=110)$ said that effective drugs against TB are available and that TB treatment is supposed to be taken for 6 to 8 months.

\section{Knowledge of factors influencing the spread of TB}

Fifty-two percent $(n=59)$ of the learners and $69 \%(n=78)$ respectively felt that contact with a person suffering from TB and overcrowded conditions favor the spread of TB.

\section{Knowledge of preventive measures against TB}

Ninety-two percent of the pupils $(n=103)$ stated that taking prophylactic drugs is a preventive measure against TB. Eighty percent $(\mathrm{n}=90)$ indicated that vaccination with Bacille de Calmette et Guérin (BCG) $(80 \%, \mathrm{n}=90)$ is a preventive measure. However, only $64 \%$ said that isolation of a patient is a preventive measure (Figure 3). Similar to "avoiding contact", it was noted that "isolation" needs to be properly explained as a preventive measure because of the possible confusion with discrimination.

\section{Knowledge of symptoms of TB}

Knowledge of symptoms of TB varied among the learners (Figure 4). Most learners ( $>86 \%$ ) knew that coughing out blood, cough with sputum, and shortness of breath are symptoms of TB, while fewer (40\%) knew that enlarged neck glands is a symptom of TB. This symptom is probably not often mentioned during educational sessions.

\section{Perceptions regarding TB}

Ninety-six percent $(\mathrm{n}=109)$ stated that anyone can get TB, whereas $3.5 \%(n=4)$ mentioned that only people with HIV can get TB. More learners $65 \%,(n=73)$ felt that people in their communities generally feel negative about a person suffering from TB, while $48 \%(n=54)$ indicated that love and care would be shown to those infected with TB. Fortytwo percent $(n=48)$ felt that most people in their communities avoid people suffering from TB. This could imply that stigma is an issue in the community, while $93 \%(n=105)$ of the learners reported that they would talk about their illness with their mother, father or health worker if they knew or suspected that they had TB. Only $1 \%(\mathrm{n}=1)$ of the learners reported that they would talk to their teachers about their illness (Figure 5).

\section{Socio-economic factors associated with knowledge and perceptions}

There was a significant difference between learners' knowledge of TB and guardians' occupation $\left(\chi^{2} 9.80, P=0.01\right)$. A higher proportion of learners $82.8 \%(24 / 29)$ and $80 \%$ (56/70) whose guardians were formally employed and farmers respectively, had knowledge on TB compared to $42.9 \%$ $(6 / 14)$ of learners whose guardians were doing business. No significant differences were observed by learners' religion, name of school, learners' age, class, and sex. It should be noted that learners from Nsiyaludzu had the lowest knowledge level when compared to other schools. A higher proportion 


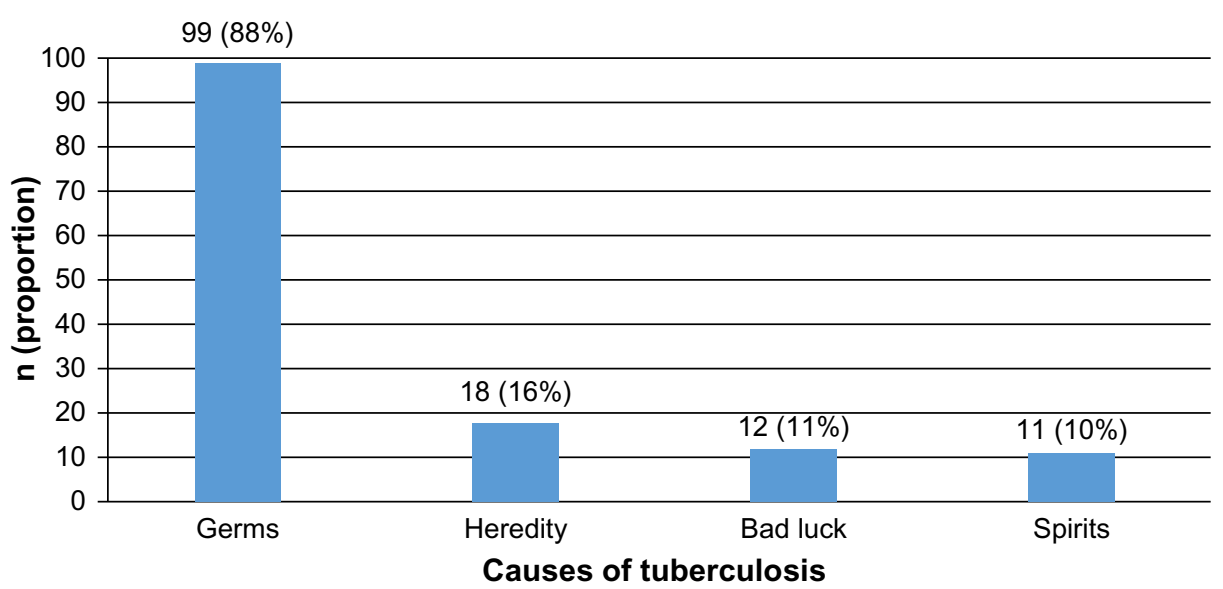

Figure 2 Knowledge of the cause of tuberculosis.

of learners with knowledge on TB were from Standard 8 and those aged 14 years. There was no significant difference between learners' perception about TB and socio-economic factors (Table 2).

\section{Discussion}

Our purpose in this study was to assess the knowledge and attitudes regarding TB among primary school learners in Ntcheu District, Malawi. Based on a sample of 113 learners in Standards 5 to 8, recruited from four schools in two TAs, we found that the knowledge of learners regarding TB was generally high. This means that learners have access to TB information. It is not surprising that almost all the learners had heard about TB because of the numerous channels that are used to convey information about TB. In this study, however, we found that there are gaps regarding knowledge on specific aspects related to symptoms, cause, cure, as well as attitudes towards the disease. We also found that not all learners knew that fever with night sweats and enlargement of neck glands are symptoms of TB. Knowledge gaps regarding

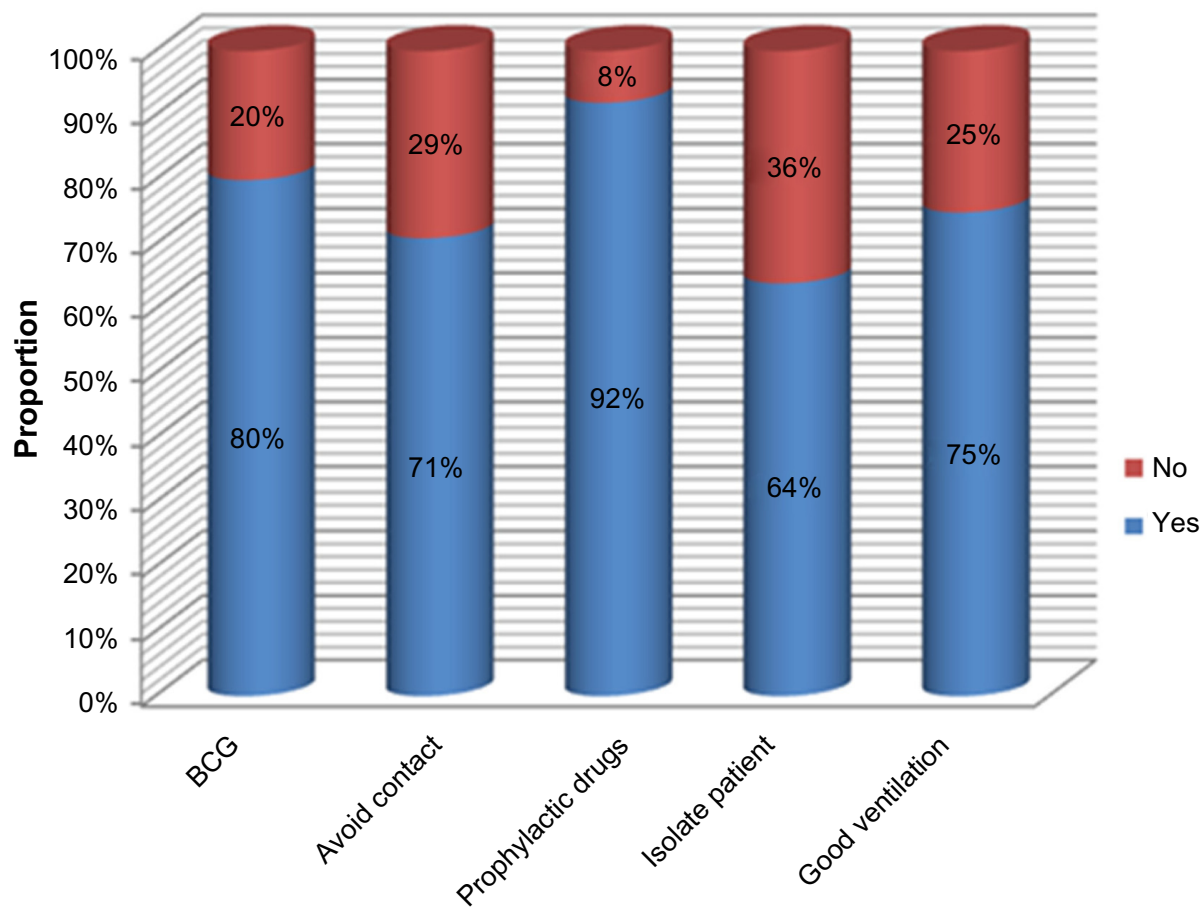

Preventive measures

Figure 3 The distribution of knowledge of preventive measures of tuberculosis. Abbreviation: BCG, Bacille de Calmette et Guérin. 


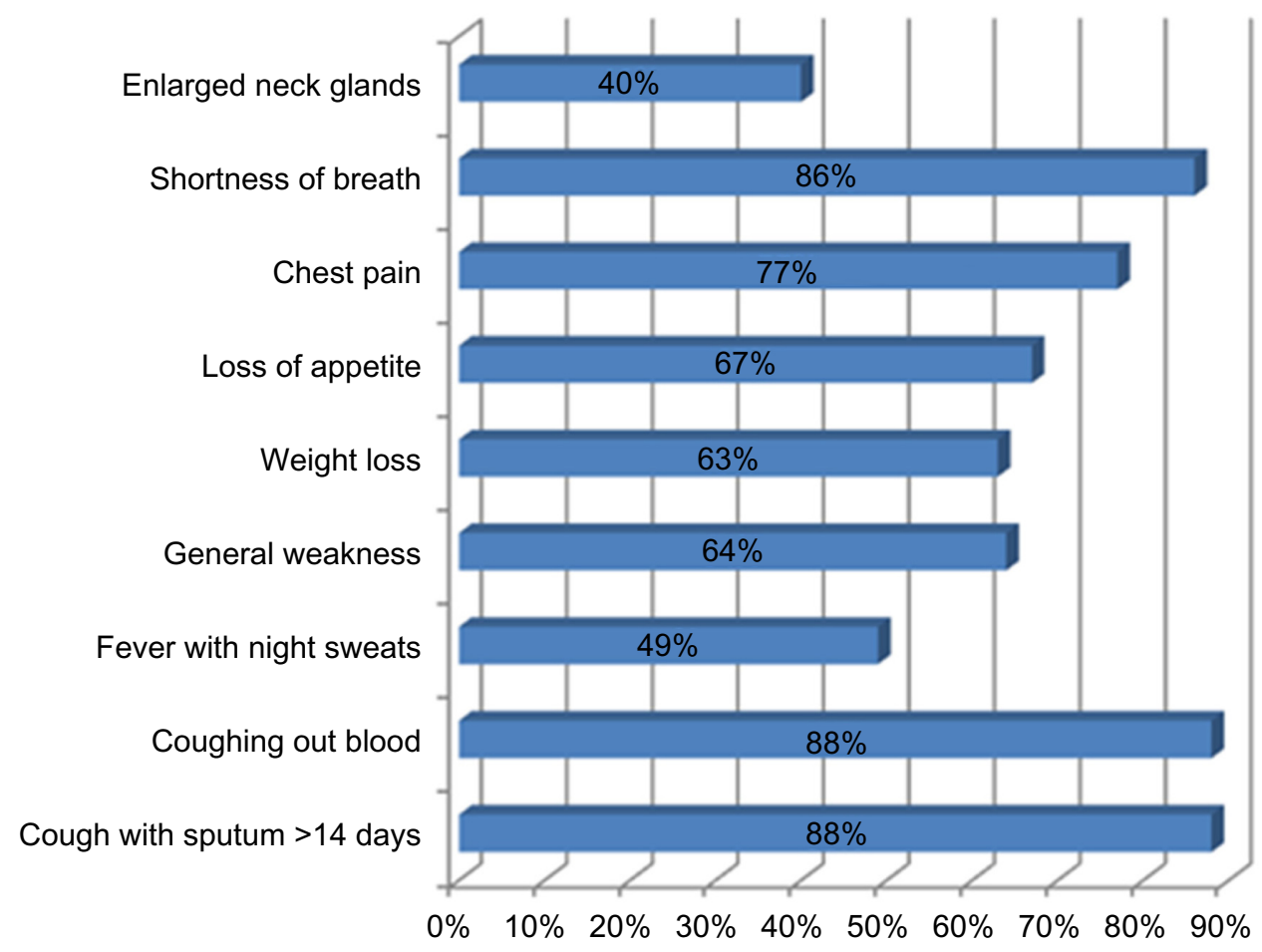

Figure 4 The distribution of knowledge of symptoms of tuberculosis.

the real cause of the disease, whereby some learners indicated that one can get the disease through spirits, from parents (heredity), and bad luck were also identified. Knowledge on how long anti-TB treatment should be taken was also low. Furthermore, the findings suggest that TB is stigmatizing, which may result in poor uptake of care and support.

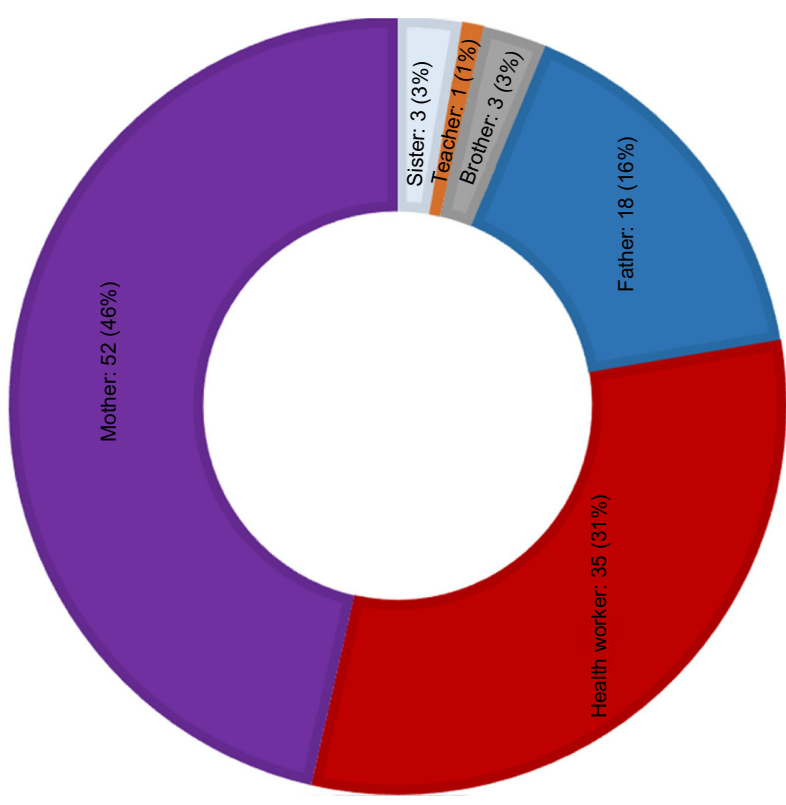

Figure 5 People who learners would talk to if they had tuberculosis. Note: Data are presented as $\mathrm{n}(\%)$.

\section{Knowledge on cause of TB}

Knowledge on the cause of TB varied despite the fact that almost all the learners had heard about the disease. Even though the majority of the learners indicated that TB is caused by germs, others said that TB is a sign of bad luck or inherited from parents or caused by spirits. This variation in the knowledge on causes of TB could be due to the prevailing beliefs about TB in the communities where the learners live. In a study by Banerjee et al, in the same district of Ntcheu similar results among adults were reported. ${ }^{16}$ This situation shows that this is a common problem among both children and adults in Ntcheu. Any interventions to address this problem will require targeting both adults and children.

\section{Knowledge on spread of TB}

Knowledge on how TB spreads was high among the learners, with the majority of them indicating that it is communicable and spreads through droplets when a patient coughs or sneezes. This finding could be an indication that the information which the learners received included how the disease is spread. Knowledge on how the disease is spread can help the learners take the necessary precautions to protect themselves from getting it. The learners were also aware that overcrowding influences the spread of the disease.

Knowledge on the dynamics of TB transmission, however, varied among the schools. Nsiyaludzu Primary School 
Table 2 Comparison of socio-economic characteristics and knowledge and perceptions about tuberculosis among the primary school learners

\begin{tabular}{|c|c|c|c|c|c|c|}
\hline \multirow[t]{3}{*}{ Factor } & \multicolumn{2}{|c|}{ Learners' knowledge } & \multirow[t]{3}{*}{$P$} & \multicolumn{2}{|c|}{ Learners' perception } & \multirow[t]{3}{*}{$P$} \\
\hline & Yes & No & & Yes & No & \\
\hline & $\mathbf{N}(\%)$ & $\mathbf{N}(\%)$ & & $\mathbf{N}(\%)$ & $\mathbf{N}(\%)$ & \\
\hline \multicolumn{7}{|l|}{ Learners' sex } \\
\hline Male & $4 \mathrm{I}(80.4)$ & $10(19.6)$ & & $26(41.9)$ & $36(58.1)$ & \\
\hline Female & $45(72.6)$ & $17(27.4)$ & 0.33 & $22(43.1)$ & $29(56.9)$ & 0.9 \\
\hline \multicolumn{7}{|l|}{ Learners' class } \\
\hline Standard 5 & $20(7 \mid .4)$ & $8(28.6)$ & & $10(35.7)$ & $18(64.3)$ & \\
\hline Standard 6 & $20(71.4)$ & $8(28.6)$ & & $15(53.6)$ & $13(46.4)$ & \\
\hline Standard 7 & $20(71.4)$ & $8(28.6)$ & 0.27 & II (39.3) & $17(60.7)$ & 0.56 \\
\hline Standard 8 & $26(89.7)$ & $3(10.3)$ & & $12(41.4)$ & $17(58.6)$ & \\
\hline \multicolumn{7}{|l|}{ Learners' age } \\
\hline$\leq \mathrm{II}$ years & $14(77.8)$ & $4(22.2)$ & & $8(44.4)$ & $10(55.5)$ & \\
\hline 12 years & $20(80.0)$ & $5(20.0)$ & & $17(4 \mid .5)$ & $24(58.5)$ & \\
\hline 13 years & $20(69.0)$ & $9(31.0)$ & 0.77 & $13(44.8)$ & $16(55.2)$ & 0.98 \\
\hline 14 years & $32(78.0)$ & $9(22.0)$ & & $10(40.0)$ & $15(60.0)$ & \\
\hline \multicolumn{7}{|l|}{ Name of school } \\
\hline Chauta & $26(89.7)$ & $3(10.3)$ & & $16(55.2)$ & $13(44.8)$ & \\
\hline Chimvano & $20(69.0)$ & $9(31.0)$ & & $12(4 \mid .4)$ & $17(58.6)$ & \\
\hline Namitengo & $22(73.3)$ & $8(26.7)$ & 0.25 & $10(33.3)$ & $20(66.7)$ & 0.39 \\
\hline Nsiyaludzu & $18(72.0)$ & $7(28.0)$ & & $10(40.0)$ & $15(60.0)$ & \\
\hline \multicolumn{7}{|l|}{ Learners' religion } \\
\hline Christian & $82(75.2)$ & $27(24.8)$ & & $46(42.2)$ & $63(57.8)$ & \\
\hline Muslim & $4(100)$ & $0(0)$ & 0.25 & $2(50.0)$ & $2(50.0)$ & 0.76 \\
\hline \multicolumn{7}{|l|}{ Guardians' occupation } \\
\hline Business & $6(42.9)$ & $8(57.1)$ & & $5(35.7)$ & $9(64.3)$ & \\
\hline Farming & $56(80.0)$ & $14(20.0)$ & 0.01 & $31(44.3)$ & $39(55.7)$ & 0.83 \\
\hline Formal employment & $24(82.8)$ & $5(17.2)$ & & $12(41.4)$ & $17(58.6)$ & \\
\hline
\end{tabular}

Notes: $\mathrm{N}=$ total number of children who participated in the study; \% = percentage of N; "Yes"/“No" columns represent presence or absence of each individual attribute.

had the least proportion of learners amongst the schools who knew that TB is communicable. This may imply that some schools are less privileged with reference to access to information regarding TB. Children who attend such schools may be put at a disadvantage of not getting the required information about TB. It is important to ensure consistency in the content of TB information in schools, radio messages, as well as during health talks in health facilities and communities.

\section{Knowledge regarding symptoms of TB}

We found that knowledge regarding symptoms of TB was high, such as cough with sputum for more than 14 days; coughing out blood; and shortness of breath. Knowledge was, however, low regarding enlargement of neck glands and fever with night sweats. The low level of knowledge regarding fever and night sweats appears surprising, especially taking into consideration that almost all the learners had heard about TB. This situation may mean that it is difficult for the learners to relate fever with night sweats with TB because of other conditions that may be present with this symptom, for example, malaria.

\section{Knowledge on cure of TB}

Consistent with knowledge on how TB is caused and spread, the majority of the learners indicated that TB is curable. Variations were however, observed in knowledge regarding the required duration of anti-TB treatment, with only $32 \%$ of the learners knowing the correct duration. Knowledge of TB treatment duration among children would help them understand the severity of the disease and the public health benefits of early diagnosis and treatment adherence. A study by Nyirenda et al among adult TB patients admitted in nonprivate hospitals in Malawi also found that less than 50\% knew the correct duration of anti-TB treatment. ${ }^{25}$ In another study by Harries et al it was reported that only $45 \%$ of children with TB completed treatment. ${ }^{26}$ This finding, therefore, reveals a major gap in knowledge on TB treatment, not only among children but also among adults. This situation implies that the information shared on TB is insufficient especially with reference to the prescribed duration of TB treatment. None of the socio-economic factors was associated with lack of knowledge that TB can cause death. 


\section{Knowledge of preventive measures against TB}

Knowledge about prevention of TB was generally high with regard to measures such as vaccination with BCG, avoiding contact, and taking prophylactic drugs. Knowledge was nonetheless low with regard to isolation of a TB patient. During the study, however, it was noted that "avoiding contact" and "isolation" was possibly confused with discrimination in the local language. The confusion regarding these terms may have contributed to the result. These terms therefore need to be properly explained to learners to convey the accurate meanings. In this study, none of the socio-economic factors were associated with knowledge of preventive measures.

The high proportion of learners who were able to indicate the preventive measures against the spread of TB may be an indication that they are well informed about TB prevention. In a study by Salaniponi et al, ${ }^{27}$ the authors found that TB prevalence was lower among children with a BCG vaccination scar. Most learners said that anyone can get TB, while $3 \%$ said that only people with HIV can get the disease. This finding shows that the information about $\mathrm{TB}$ which the learners received contained aspects concerning their risk of getting the disease.

The small proportion of learners who said that only people with HIV can get TB contrasts the finding by Bond et $\mathrm{al}^{14}$ among pupils in Zambia that found that learners were less sure about the link between TB and HIV. From a different perspective, however, one could view the low number of learners who indicated that only people with HIV can get TB as a reflection of lack of knowledge of the association between TB and HIV.

\section{Perception regarding TB}

We also found that TB is highly stigmatizing. This was evident from the finding that $65 \%$ of the learners perceived that people in their community feel negative about a person suffering from TB. This situation is worrisome because stigma can cause TB patients to seek treatment and care from inappropriate providers.

The study also found that the learners would talk to their parents or health workers about their condition if they suspected they had TB. Only $1 \%$ of the learners, however, said they would talk to their teacher. Hesam et $\mathrm{al}^{28}$ found that most students could talk to health staff about their disease if they knew or suspected that they had TB, while $42 \%$ said they would talk to their parents, and $6.2 \%$ indicated that they would not talk to anyone about it. Bond et al, ${ }^{14}$ in Zambia, found that children were not very comfortable talking about TB with adults in their respective homes. This finding suggests that learners are generally not free to talk to their teachers about their health-related matters. Learners ought to regard teachers as their confidants on health issues. To address this problem, there has to be a deliberate effort to include improving the teacher-learner relationship on health matters.

Despite that, all learners indicated that one should seek care for TB at a health facility. Moreover, $97 \%$ said the disease is curable, whereas $31 \%$ of the learners indicated that they would consult a health worker if they suspected they had TB. This may mean that they are dependent on their guardians concerning care-seeking behaviors. This agrees with the study by Nyirenda et al ${ }^{25}$ which reported low attendance at a child TB contact clinic.

\section{Socio-economic factors associated with knowledge and perceptions}

There was a significant difference between learners' knowledge of TB and guardians' occupation. This may imply that more people who were farmers and those with formal employment discuss health-related matters with their children at home. Even though one third of learners in Standards 5 and 6 were less knowledgeable about TB compared to those in Standard 8, this was not statistically significant. Learners' knowledge may therefore be the same across all the four classes. Learners' perception of TB was not associated with any of the socio-economic factors tested, showing that none of the socio-economic factors investigated influence learners' perception of TB. ${ }^{29}$

\section{Limitations}

The study tool was translated into the local language. Interpretation of some of the questions, eg, "isolation of patient", "TB is a communicable disease", and "avoiding contact with a person suffering from TB", may have varied due to the absence of exact words in "Chichewa", the local language spoken in the area. In addition, this study was conducted in only four schools in one district in Malawi, so its generalizability beyond this district in Malawi may be limited.

\section{Conclusions and recommendations}

Our findings have implications on teaching children about TB in schools, as well as delivery of TB information, education, and communication in the communities. The knowledge gaps identified may have origins in the content of the school curricula, delivery mode or content of information, education, 
and communication. Lack of association between knowledge and class shows that information, education, and communication have an important role regarding learners' knowledge of TB. Therefore, social mobilization needs to filter through to the primary school children so as to improve TB awareness and enhance TB control efforts.

\section{Acknowledgments}

We are grateful to all primary school children who participated in this study and all teachers who facilitated the process. We thank the National Commission for Science and Technology for providing the funds to support The FindTB project in Ntcheu, Malawi.

\section{Disclosure}

This manuscript originates from a Master's thesis by Dr Susan Kambale. The authors report no other conflicts of interest in this work.

\section{References}

1. World Health Organisation. Global Tuberculosis Control 2011. Geneva: World Health Organization; 2011. Available from: http://apps.who. int/iris/bitstream/10665/44728/1/9789241564380_eng.pdf. Accessed February 9, 2016.

2. World Health Organisation. Implementing the WHO Stop TB Strategy: A Handbook for National Tuberculosis Control Programs. Geneva: World Health Organization; 2008. Available from: http://apps.who. int/iris/bitstream/10665/43792/1/9789241546676_eng.pdf. Accessed February 9, 2016.

3. Marais B, Hesseling A, Gie R, Schaaf H, Beyers N. The burden of childhood tuberculosis and the accuracy of community-based surveillance data. Int J Tuberc Lung Dis. 2006;10(3):259-263.

4. Swaminathan S, Rekha B. Pediatric tuberculosis: global overview and challenges. Clin Infect Dis. 2010;50 (Supp1 3):S184-S194.

5. Newton SM, Brent AJ, Anderson S, Whittaker E, Kampmann B. Paediatric tuberculosis. Lancet Infect Dis. 2008;8(8):498-510.

6. Singh M, Mynak ML, Kumar L, Mathew JL, Jindal SK. Prevalence and risk factors for transmission of infection among children in household contact with adults having pulmonary tuberculosis. Arch Dis Child. 2005;90(6):624-628.

7. Sinfield R, Nyirenda M, Haves S, Molyneux EM, Graham SM. Risk factors for TB infection and disease in young childhood contacts in Malawi. Ann Trop Paediatr. 2006;26(3):205-213.

8. Altet MN, Alcaide J, Plans P, et al. Passive smoking and risk of pulmonary tuberculosis in children immediately following infection. A case-control study. Tuber Lung Dis. 1996;77(6):537-544.

9. Zachariah R, Spielmann MP, Harries AD, Salaniponi FL. Voluntary counselling, HIV testing and sexual behaviour among patients with tuberculosis in a rural district of Malawi. Int J Tuberc Lung Dis. 2003;7(1):65-71.

10. World Health Organization. Global Tuberculosis Control 2010. Geneva: World Health Organization; 2010. Available from: http://www.who.int/ tb/features_archive/global_report2010_launch_11nov10/en/.Accessed August 28, 2015.
11. Harries AD, Parry C, Nyongonya Mbewe L, et al. The pattern of tuberculosis in Queen Elizabeth Central Hospital, Blantyre, Malawi: 1986-1995. Int J Tuberc Lung Dis. 1997;1(4):346-351.

12. Nyirenda TE, Harries AD, Gausi FK, et al. Auditing the new decentralised oral treatment regimens in Malawi. Int $J$ Tuberc Lung Dis. 2004;8(9):1089-1094.

13. Storla DG, Yimer S, Bjune GA. A systematic review of delay in the diagnosis and treatment of tuberculosis. BMC Public Health. 2008;8:15.

14. Bond V, Chilikwela L, Simwinga M, et al. Children's role in enhanced case finding in Zambia. Int J Tuberc Lung Dis. 2010;14(10): $1280-1287$.

15. Naidoo S, Taylor M. Association between South African high-school learners' knowledge about tuberculosis and their intention to seek healthcare. Glob Health Action. 2013;6:21699.

16. Banerjee A, Harries AD, Nyirenda T, Salaniponi FM. Local perceptions of tuberculosis in a rural district in Malawi. Int J Tuberc Lung Dis. 2000;4(11):1047-1051.

17. Abebe G, Deribew A, Apers L, et al. Knowledge, health seeking behavior and perceived stigma towards tuberculosis among tuberculosis suspects in a rural community in southwest Ethiopia. PLoS One. 2010;5(10):e13339.

18. Steen TW, Mazonde GN. Health seeking behaviour in Batswana with pulmonary tuberculosis. Soc Sci Med. 1999;48(2):163-172.

19. Claessens NJ, Gausi FF, Meijnen S, Weismuller MM, Salaniponi FM, Harries AD. Traditional healers and pulmonary tuberculosis in Malawi. Malawi Medical Journal. 2002;13(4):7-8.

20. Salaniponi FM, Christensen JJ, Gausi F, Kwanjana JH, Whitty CJ, Harries AD. "No sex please-we're on TB treatment". Trans R Soc Trop Med Hyg. 2000;94(3):250-251.

21. Brouwer J, Boeree M, Kager P, Varkevisser C, Harries A. Traditional healers and pulmonary tuberculosis in Malawi. Int J Tuberc Lung Dis. 1998;2(3):231-234.

22. National Statistical Office. 2008 Population and Housing Census. Zomba, Malawi; 2008. Available from: http://www.nsomalawi. mw/2008-population-and-housing-census/107-2008-population-andhousing-census-results.html. Accessed November 30, 2015.

23. Bartlett JE, Kotrlik JW, Higgins CC. Organizational research: Determining appropriate sample size in survey research. Information Technology, Learning, and Performance Journal. 2001;19(1):43-50.

24. National Statistical Office and ICF Macro. Malawi Demographic and Health Survey 2010. NSO and ICF Macro: Zomba, Malawi, and Calverton, Maryland, USA; 2011. Available from: https://dhsprogram. com/pubs/pdf/FR247/FR247.pdf. Accessed November 30, 2015.

25. Nyirenda M, Sinfield R, Haves S, Molyneux E, Graham S. Poor attendance at a child TB contact clinic in Malawi. Int J Tuberc Lung Dis. 2006;10(5):585-587.

26. Harries A, Graham S, Weismuller M, et al. Childhood tuberculosis in Malawi: caseload, diagnostic practices and treatment outcomes. Malawi Medical Journal. 2005;17(4):119-124.

27. Salaniponi FM, Kwanjana J, Veen J, Misljenovic O, Borgdorff MW. Risk of infection with Mycobacterium tuberculosis in Malawi: national tuberculin survey 1994. Int J Tuberc Lung Dis. 2004;8(6): 718-723.

28. Hesam S, Hashemi AB, Khorgoei T, et al. Knowledge and attitudes towards tuberculosis among secondary school students in rural areas in Hormozgan, Southern Iran. International Electronic Journal of Medicine. 2012;1(1):11-16.

29. Kambale S. Assessment of the knowledge and perceptions about tuberculosis among primary school children in Ntcheu District, Malawi [master's thesis]. 2012. South Africa: School of Public Health University of the Western Cape. 


\section{Publish your work in this journal}

The Journal of Multidisciplinary Healthcare is an international, peerreviewed open-access journal that aims to represent and publish research in healthcare areas delivered by practitioners of different disciplines. This includes studies and reviews conducted by multidisciplinary teams as well as research which evaluates the results or conduct of such teams or healthcare processes in general. The journal covers a wide range of areas and welcomes submissions from practitioners at all levels, from all over the world. The manuscript management system is completely online and includes a very quick and fair peer-review system. Visit http://www.dovepress.com/testimonials.php to read real quotes from published authors.

Submit your manuscript here: http://www.dovepress.com/journal-of-multidisciplinary-healthcare-journal 